\title{
Beatriz Aracil Varón. "Yo, don Hernando Cortés». Reflexiones en torno a la escritura cortesiana. Madrid: Iberoamericana / Vervuert (Biblioteca Indiana), 2016.
}

En este libro Beatriz Aracil Varón hace un estudio sobre la obra escrita por Hernán Cortés, desde los documentos de 1519 hasta el testamento del conquistador, recavando datos sobre los textos que han jugado un papel crucial en la configuración del personaje histórico/literario, y a su vez analizando la construcción del mito a través del corpus textual cortesiano. De esta manera, a lo largo de los cuatro capítulos que conforman el estudio presentado en este libro, se esclarece progresivamente la evolución del "yo» que Hernán Cortés construye en su discurso. Volver a los textos coloniales es siempre una aventura productiva, y este libro lo demuestra con creces.

Teniendo en cuenta la complejidad del corpus textual en torno a la figura de Hernán Cortés, en el primer capítulo Aracil traza un breve recorrido por el proceso de recuperación de textos que usa en su estudio de la escritura de y sobre Cortés. A partir de las primeras relaciones impresas, marca la trayectoria del discurso cortesiano en la reescritura de los cronistas, tanto de su tiempo como de las reediciones en el siglo XVIII. Además incorpora un apartado dedicado al rescate documental y a la tendencia actual de recuperación de textos sobre la figura de Cortés. Finalmente, cierra este capítulo negando la propuesta de Christian Duverger, quien le atribuye al conquistador gran parte de la autoría de la Historia verdadera de la conquista de la Nueva España. Consciente de las diferentes aproximaciones al estudio de este corpus textual, la autora recopila los textos sobre el personaje histórico y literario teniendo en cuenta diferentes corrientes, tanto las favorables a la figura del conquistador como las que se oponen a la herencia colonial y reclaman las culturas prehispánicas. De esta manera, Aracil Varón logra delinear al sujeto narrativo a través de las obras cortesianas.

En el segundo capítulo la crítica se centra en la conexión del «yo» (Hernán Cortés) con su propia escritura desde los primeros documentos que se tienen. Analizando las Cartas de relación la autora demuestra cómo se construye el sujeto mítico, Hernán Cortés, mientras presenta la historia de un solo hombre, él. La autora sustenta su idea del vínculo del yo con la escritura en el corpus cortesiano atendiendo al discurso oral en las Cartas de relación, y cómo el sujeto exhibe sus cualidades en el plano religioso y en el militar. Además, describe la manera en que Cortés se define como siervo del rey que cumple con la legalidad, e insiste en presentarse como el responsable de la ampliación del imperio. A través del análisis de la redacción del encuentro entre Cortés y Moctezuma, Aracil Varón demuestra que "Cortés reafirma el vínculo que lo une a su señor como real vasallo» (82), pues el conquistador coloca, en su discurso, a Moctezuma bajo la corona española, con lo cual enmarca lo azteca como parte ya del imperio ibérico. Así señala con eficacia cómo Cortés se sumerge de lleno en la Historia a través del uso de la primera persona en sus escritos.

Después de presentar y analizar todo este corpus textual y la escritura del renombrado conquistador, en el tercer capítulo Aracil Varón profundiza en la formación de la imagen del héroe y cómo éste se posiciona con respecto a la Historia. La crítica distingue tres modelos que Hernán Cortés utiliza para su propia caracterización: el héroe militar y político, el mundo clásico y el vasallo ejemplar. Así identifica magistralmente los motivos y las fuentes de las que se vale Cortés para crear una figura literaria de sí mismo. En el último apartado de este capítulo se exponen los recursos retórico-estilísticos que le sirven a Cortés para su construcción mítica, recalcando su acercamiento filológico y sobre todo el uso del sujeto gramatical. Todos estos métodos de escritura indentificados a lo largo del capítulo, demuestran que «Cortés se inscribe a sí mismo en la Historia como héroe que conquista una gran nación para su emperador y la gobierna con justicia» (124).

Para terminar, la autora recalca de nueva cuenta la construcción del «yo» a lo largo de los textos 
cortesianos, sólo que ahora centra su análisis en el posicionamiento de Cortés con respecto al territorio americano y su postura de superioridad con respecto al otro, al indígena. En este trayecto entendemos mejor cómo el «yo» cortesiano se construye en base a estos dos nuevos fenómenos que encuentra, los cuales también forman parte de sus dos motivaciones personales: la construcción de un sujeto y su incursión en la Historia. Para comprobarlo, la autora enfatiza la percepción que Cortés refleja de sí mismo en textos paralelos a las Cartas de relación. La autora postula que el «yo» al que se da forma en dichos textos y la evolución que sufre es delimitado por el poder imperial (Carlos V), el indígena (el otro) y por el nuevo territorio (desde el punto de vista del colonizador). La comunicación que Cortés mantiene con estas tres realidades es para Aracil lo que determina la transformación que sufre ese sujeto literario creado por él mismo y su vínculo con el nuevo territorio, aunque «el yo cortesiano no logró nunca abandonar la conciencia inicial de América como un Nuevo Mundo" (172).
En defitiva, "Yo, don Hernando Cortés». Reflexiones en torno a la escritura cortesiana es un texto útil para observar cómo la figura del conquistador de México, la que nos llega hoy día a los lectores, viene configurada por un acto consciente de parte del que escribe. Con destreza y total dominio de sus fuentes, Aracil Varón resalta los métodos y recursos literarios utilizados por este personaje para introducirse en la Historia, y así nos ofrece un estudio completo de la obra escrita por y sobre sí mismo y sus hazañas, al igual que lo escrito por otros sobre él. Al trazar el recorrido de la construcción del «yo» que Cortés ejecuta a lo largo de su escritura, el libro dialoga con trabajos centrales en torno a la escritura cortesiana - como el de Beatriz Pastor Bodmer, por ejemplo, y en el trayecto crítico nos ubica en el epicentro de una prosa novedosa que, a pesar del tiempo y la distancia, sigue cautivando a nuevos lectores en el siglo XXI.

Elena Peña-ArgüEso University of North Carolina at Chapel Hill 